\title{
A new atmospheric pollen monitoring network for South Africa
}

\author{
Jonny Peter (일 ${ }^{1}$ and Dilys Berman (1) ${ }^{2}$ \\ Allergy Immunology Unit, UCT Lung Institute \\ 1Jonny.Peter@uct.ac.za \\ 2Dilys.Berman@uct.ac.za
}

https://doi.org/10.17159/caj/2019/29/2.7645

\section{Introduction}

It is estimated that 4 out of 5 children in the world are breathing unsafe air (https://www.who.int/airpollution/en/). The majority of focus around air quality examines air pollutants like $\mathrm{SO}_{2}$, $\mathrm{CO}$, and particulate matter with attendant health problems. However, there are other bioaerosols such as pollen and fungal spores that also affect health. Modelling data from Europe indicate that climate change will dramatically increase pollen levels by as much as 4-5 fold (Katelaris and Beggs 2018). Greater attention to this aspect of air quality is thus urgently needed in South Africa.

\section{Pollen allergy and climate change}

Airborne pollen and fungal spores are known as aeroallergens. These aeroallergens may trigger asthma (airway), allergic rhinitis (nose) and conjunctivitis (eye) in an estimated $20-30 \%$ of South Africans (Ait-Khaled et al 2007). Pollen, fungal spores and house dust mites and the three commonest aeroallergens that allergy sufferers react too. When pollen is inhaled and comes into contact with the mucous membrane of the respiratory tract, it rapidly extends a pollen tube, often within 90 seconds (Solomon 2005). The tube releases recognition substances in the form of enzymes, which are predominantly proteins and glycoproteins. It is these proteins and glycoproteins that cause an immune response to be mounted in allergic individuals as briefly outlined in Figure 1.
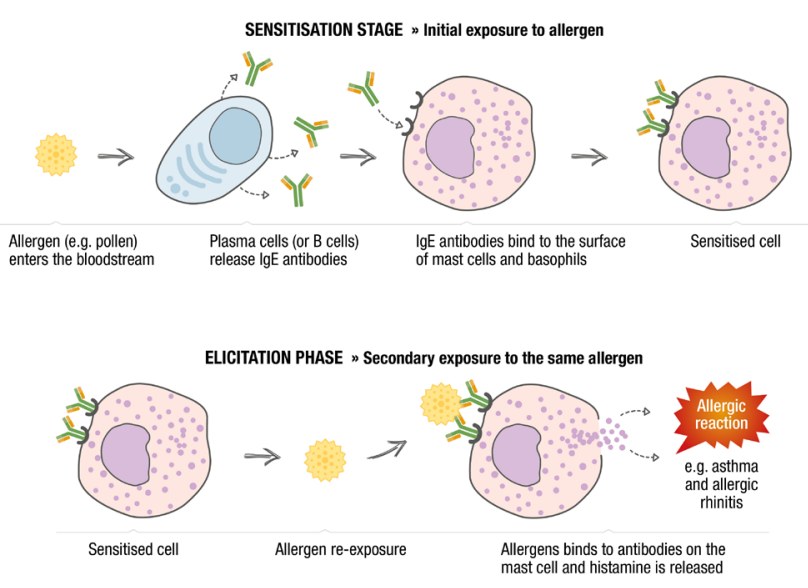

Figure 1: Schematic representation of the basic immune mechanisms of an immediate type-1 allergic reaction, resulting in the rapid release of histamine and other substances inducing the typical clinical allergic pattern of symptoms (From Jeurink 2005)
The pollen of plants that have brightly coloured flowers, pollinated by insects, birds or small mammals like mice, rarely trigger allergy. Pollen that is allergenic is usually produced in large quantities, is windborne and it is strongly associated with weather parameters, especially temperature, humidity, rainfall and wind speed and direction. Grass is a good example of an allergenic pollen and is the major pollen allergen in many countries. Climate Change is altering weather patterns and thereby changing the length of the pollen season, as some plants increase their pollen production under conditions of increased $\mathrm{CO}_{2}$ or higher temperatures (Albertine et al 2014). The impact of these changes is that exposure of the allergic individual to pollen allergens is likely to increase. This is especially relevant to ragweed, an invasive weed that is known to have been introduced to South Africa but has not been detected at pollen monitoring sites so far. Ragweed is the major weed allergen in many Northern Hemisphere countries. The pollen season for grasses and trees is likely to lengthen and become less predictable as a consequence of Global Warming. For these reasons, it is becoming increasingly important for countries to routinely measure pollen in the air, especially focused on the most densely populated cities.

\section{Pollen and pollutants}

Air pollution is a growing global concern; and climate change looks set to make pollen an increasing problem. What is worse, is that there appears to be a synergist effect of air pollutants on allergic responses to pollen proteins. Epidemiological data indicates that allergic subjects living close to major roads, with exposure to diesel exhaust particles, have more severe allergic disease (Motta et al 2006). One of the drivers of this surge in symptoms appears to be the interaction between pollen and diesel exhaust particles. The mechanism that brings about this effect is damage to the exine, or outer cell wall of the pollen grain, rendering the pollen more fragile, so that it readily fractures and releases allergenic cytoplasmic particles (Motta et al 2006). Aggravation of asthma and allergic rhinoconjunctivitis has also been linked to exposure to particulate matter (PM); and in several SA provinces and cities, due to veld fires and burning biomass, PM levels exceed WHO recommendations (Baldacci et al 2015). The size of the particles (in $\mu \mathrm{m}$ ) aerosolised is important in the consequent airway/allergic effects, as the size of the particles impact their ability to penetrate into the respiratory tract. $\mathrm{PM}_{10}$, and $\mathrm{PM}_{2.5}$ only penetrate the upper respiratory tract, while ultrafine particles $\mathrm{PM}_{0.1}$ are able to penetrate the alveoli. 
These smallest particle, $\mathrm{PM}_{0.1}$ can lead to molecular changes and thought to be key to changing the way the immune system interacts with allergen at the airway interface (Baldacci et al 2015).

\section{Pollen monitoring in seven South African cities}

Pollen monitoring has always been sporadic in South Africa. Several areas have never been monitored e.g. Eastern Cape or Mpumalanga; while others Gauteng were last consistently monitored in the 1990s (Potter and Cadman). This limited local data and increasing realisation of the changing environment and likely worsening impact on health has led us to launch a national campaign to monitor pollen across SA. The project was initiated and is being led by the Allergy and Immunology Unit at the University of Cape Town Lung Institute; and includes clinicians, aerobiologist, palynologists and students at six universities. Funding has been raised through corporate sponsorship. In August 2019 the National Pollen Campaign established pollen monitoring sites where pollen spore traps were set up in: Johannesburg, Pretoria, Durban, Bloemfontein, Kimberley and Port Elizabeth and together with the existing Cape Town site a pollen monitoring network has been created. Teams of clinicians and scientists in each city are using 7 day recording volumetric spore traps, mounted on rooftops to trap the pollen and fungal spores contained in a measured air volume onto sticky cellulose strips. The harvested strips are examined using light microscopes to identify and count the air spora and to produce the daily pollen count, which is the number of pollen grains contained in one cubic meter of air per day. The weekly pollen counts, together with information on how and why pollen monitoring is being done, key facts for allergy sufferers and about allergenic plants are available through our website - www.pollencount.co.za. This makes the information readily available to individual patients; clinicians who treat patients with allergic disease and scientists. This is already leading to increased diagnosis and triaging of patients to correct treatment.

\section{Vegetation biomes and SA cities}

South Africa has a high range of biodiversity relative to its size and the seven cities chosen as the initial pollen sampling sites are both large urban provincial capital centres, but also reflect many of the SA different biomes. Fynbos is a feature of the Western Cape, Durban is in a subtropical climate zone, Pretoria and Johannesburg are in Grassland/ Savanna regions. Kimberley and Bloemfontein are close to maize crops and Port Elizabeth is a melting pot of vegetation biomes. Tree pollen from the sites is predominantly from Northern Hemisphere aliens that have been introduced, but white stinkwood: Celtis africana and kareeboom or Rhus, now named Searsia, have been identified from pollen monitoring in South Africa.

\section{Where to from here? Pollen Samplers for Mpumalanga, Limpopo and North West Province}

A major strategic aim of the project is to have consistent pollen monitoring in at least one site for each of SA nine provinces. Thus, we are looking to expand to the additional three provinces that are not currently part of the National Pollen Campaign. Further funding and logistical planning is being undertaken, and we would welcome contributes from interested scientists. A further aim is to continue the pollen monitoring programme for five years. Undoubtedly the longer the project continues and the wider its reach, the more impact it is likely to have. We believe that initiatives like this, striving to achieve long-term national pollen data will be of major benefit to individual patients, climate change scientists and healthcare and environmental policy makers assessing the impact of climate change on allergenic pollen in SA and consequently its potential future impact on human health.

\section{References}

Katelaris $\mathrm{CH}$, Beggs PJ. Climate change: allergens and allergic diseases. Intern Med J. 2018;48(2):129-34.

Ait-Khaled N, Odhiambo J, Pearce N, Adjoh KS, Maesano IA, Benhabyles B, et al. Prevalence of symptoms of asthma, rhinitis and eczema in 13- to 14-year-old children in Africa: the International Study of Asthma and Allergies in Childhood Phase III. Allergy. 2007;62(3):247-58.

Solomon WR. Airborne pollen: a brief life. J Allergy Clin Immunol. 2002;109(6):895-900.

Albertine JM, Manning WJ, DaCosta M, Stinson KA, Muilenberg $M L$, Rogers CA. Projected carbon dioxide to increase grass pollen and allergen exposure despite higher ozone levels. PLoS One. 2014;9(11):e111712.

Motta AC, Marliere M, Peltre G, Sterenberg PA, Lacroix G. Trafficrelated air pollutants induce the release of allergen-containing cytoplasmic granules from grass pollen. Int Arch Allergy Immunol. 2006;139(4):294-8.

Baldacci S, Maio S, Cerrai S, Sarno G, Baiz N, Simoni M, et al. Allergy and asthma: Effects of the exposure to particulate matter and biological allergens. Respir Med. 2015;109(9):1089-104.

Potter PC, Cadman A. Pollen allergy in South Africa. Clin Exp Allergy. 1996;26(12):1347-54.

Jeurink, Prescilla V., and Huub FJ Savelkoul. "Induction and regulation of allergen-specific IgE." Allergy Matters: New approaches to allergy prevention and management 10 (2005) p18. 